\title{
PKWeir and flap gate spillway for the Gage II Dam
}

\author{
V. Dugué, F. Hachem \& J-L. Boillat \\ Laboratory of Hydraulic Constructions (LCH), Ecole Polytechnique Fédérale de Lausanne (EPFL), \\ Switzerland \\ V. Nagel, J-P. Roca \& F. Laugier \\ Electricité de France (EDF), Centre d'Ingénierie Hydraulique, Savoie Technolac, Le Bourget-du-Lac, \\ France
}

\begin{abstract}
The Gage II concrete arch dam shows some limiting constraints in its structural behavior when submitted to particular hydrostatic and thermal load conditions. Its sensitivity to low temperature has led to determine two different maximum water levels during winter and summer, respectively. Therefore, a new complementary spillway, composed by a PKWeir and a flap gate weir has been designed by EDF and optimized using a physical scaled model at LCH. The experimental tests have been carried out for different configurations of the spillway. The output flow capacities of the PKWeir and the flap gate weir including their interaction through the restitution channel have been also investigated. The geometric optimization process has been conducted on several spillway parameters: number of the PKWeir units, its position relative to the flap gate weir, and the height, width and bottom slope of the restitution channel. The tested configurations have been compared based on their flow output capacity.
\end{abstract}

\section{PROJECT DESCRIPTION}

\subsection{Context}

The Gage II dam, operated by Electricité de France, is located on the Gage River in the Ardèche department in France (Fig. 1a). This concrete arch dam, of $40 \mathrm{~m}$ high, was built in 1967. Flood events are actually evacuated by a free spillway over the dam crest, with a capacity of $230 \mathrm{~m}^{3} / \mathrm{s}$ (Fig. 1b).
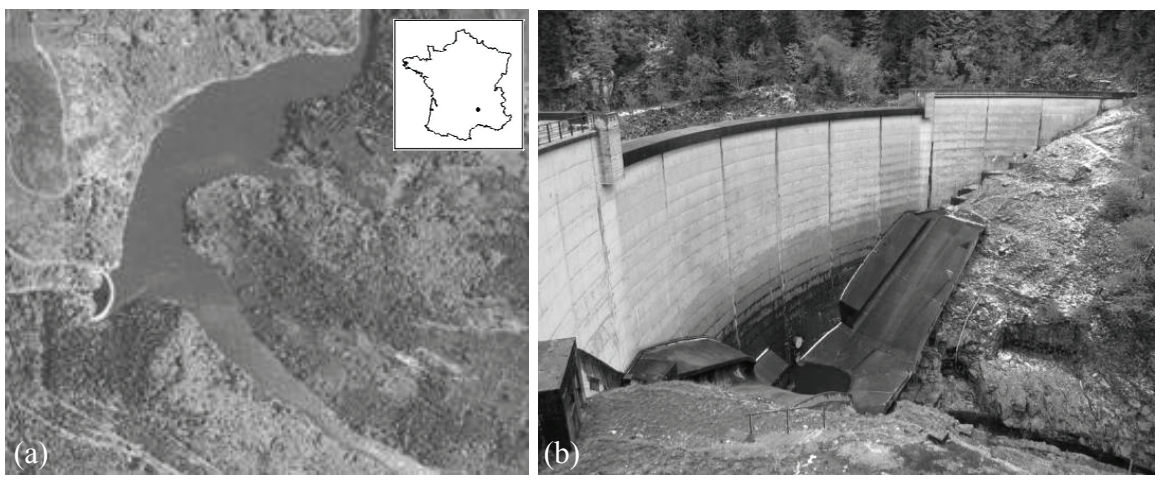

Figure 1. a) Aerial view of the Gage II dam and reservoir. b) Photo of the downstream face of the dam and the existing crest spillway.

The particular characteristics of the dam (high slenderness ratio and high developed crest length over height ratio) lead to important high tensile stresses at the upstream foot of the arch. This phenomenon is particularly marked in winter when the contraction of the arch concrete promotes a downstream tipping displacement of the dam. Therefore, it has been decided to low- 
er the water operation level by $5 \mathrm{~m}$ during cold periods, in order to decrease the water pressure loads on the dam. The solution promoting the construction of an additional new spillway on the right bank side of the dam has been adopted.

The design of the new spillway was done according to the results of a recent hydrologic study of the Gage II watershed. The estimated new extreme floods are higher than the original design values of the existing spillway. For example, the new design peak flow for a 1000 years return period is evaluated to $675 \mathrm{~m}^{3} / \mathrm{s}$ and is approximately three times higher than the previous one.

\subsection{The concept of the new spillway}

The design of the new additional spillway is an axial arrangement of a PKWeir and a flap gate weir overtopping in a side channel. The latter is connected to an underground evacuation tunnel of approximately $200 \mathrm{~m}$ length (Fig. 2). The PKWeir spillway is an efficient measure to reduce the total spillway width and the rock excavation volume needed for the side channel construction (Falvey 2003, Leite et al. 2009).

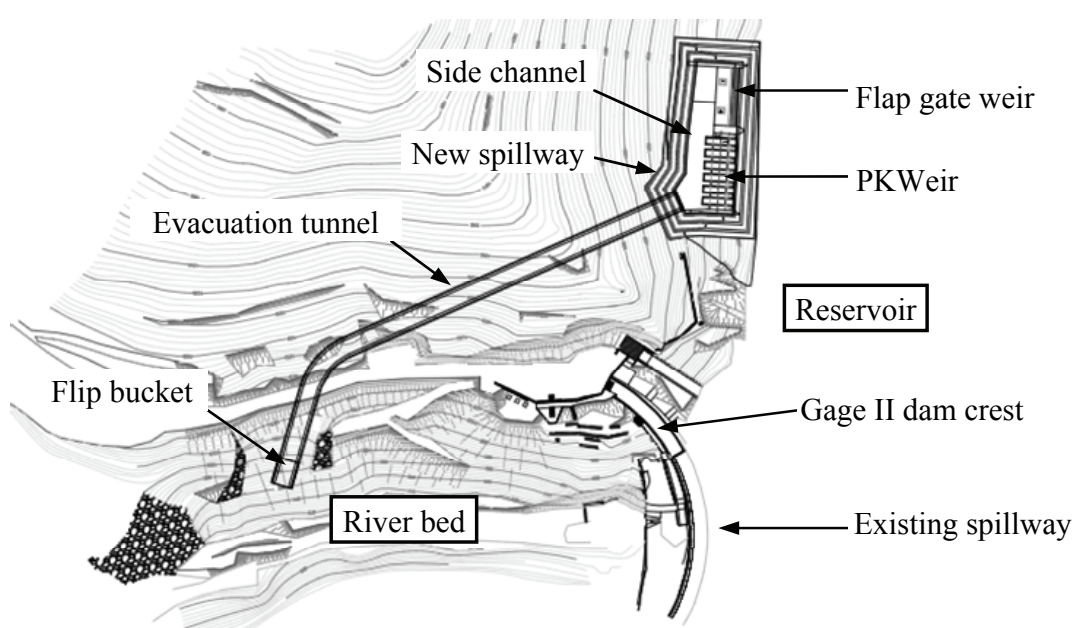

Figure 2. Plan view of the dam with the new spillway on its right bank side.

The new spillway (Fig. 3) will be operated as follows: (i) During hot season, the flap gate will be closed (high position) and the main floods discharge will be evacuated by the existing and new spillways, (ii) during cold season, the flap gate will be opened (low position) and the reservoir operation level will be lowered down to el. $1005 \mathrm{~m}$., $5 \mathrm{~m}$ below the hot season operation level (el. $1010 \mathrm{~m})$. Floods discharge will then be evacuated only through the flap gate weir.

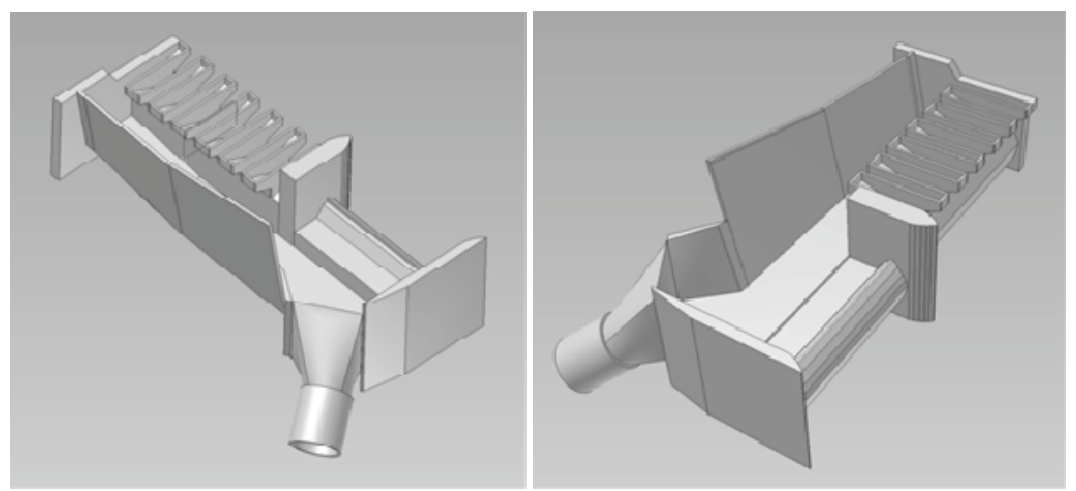

Figure 3. 3D views of the new spillway with the PKWeir and flap gate weir combination.

The new evacuation system (weirs, side channel and tunnel) is designed and checked for 1000 years return periods floods and its sensitivity to more extreme floods (5000 years return periods floods) is also considered. The water level and discharge constraints for hot and cold seasons are listed in Table 1. 
$\underline{\text { Table 1. Design objectives for the new additional spillway }}$

\begin{tabular}{cccc}
$\begin{array}{c}\text { Flood return } \\
\text { period }\end{array}$ & Season & $\begin{array}{c}\text { Maximum Water } \\
\text { Level (MWL) } \\
{[\mathrm{m}]}\end{array}$ & $\begin{array}{c}\text { Peak flood discharge to be eva- } \\
\text { cuated by the new spillway } \\
{\left[\mathrm{m}^{3} / \mathrm{s}\right]}\end{array}$ \\
\hline 1000 & Hot & 1011.50 & 459 (PKWeir + flap gate) \\
5000 & Hot & 1011.77 & 557 (PKWeir + flap gate) \\
1000 & Cold & 1009.00 & 468 (Flap gate only) \\
5000 & Cold & 1009.64 & 610 (Flap gate only) \\
\hline
\end{tabular}

\subsection{Preliminary design}

The preliminary design of the new spillway showed that a flap gate weir around $25 \mathrm{~m}$ wide is sufficient to evacuate the 1000 years return period flood (United States Department of the Interior 1987, Hager \& Schleiss 2009). A flap gate width of $20 \mathrm{~m}$ has been adopted as a minimum start value for the optimization process to be carried out on the physical model of the spillway.

For the PKWeir, the design procedure was aiming to obtain the best economical and technical configuration by minimizing the width $\mathrm{W}$ and maximizing the height $\mathrm{P}$ shown on Figure 4. Different PKWeir geometries have been previously tested numerically using the Flow-3D model (Flow-3D 2010). The results reveal that a PKWeir of $34 \mathrm{~m}$ width and $6 \mathrm{~m}$ height could evacuate the design flood discharge under a water level head below the authorized maximum value. They show that the expected specific discharge referred to the width $W$ is around $15 \mathrm{~m}^{3} / \mathrm{s} / \mathrm{m}$ for a water head of $1.5 \mathrm{~m}$. The other fundamental geometry parameters for the PKWeir keys or units are depicted in Table 2. It should be emphasized here that PKWeirs of $6 \mathrm{~m}$ height have never been built before in France. A height of $4 \mathrm{~m}$ is generally used.

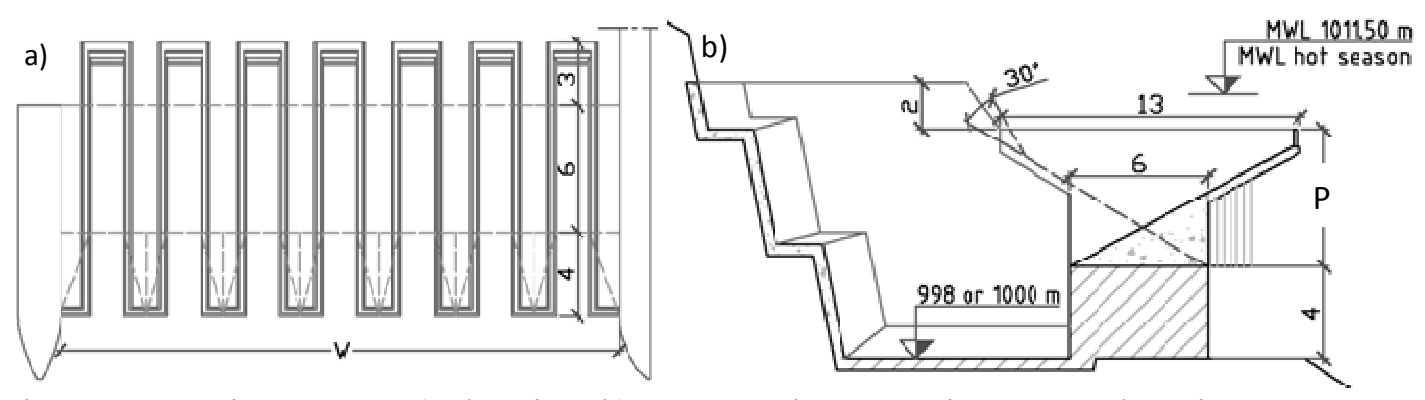

Figure 4. PKWeir geometry: a) Plan view; b) Transversal cross-section at an outlet unit

Table 2. Geometric parameters of the PKWeir units adopted for the new spillway.

\begin{tabular}{llc}
\hline Nomenclature* & & {$[\mathrm{m}]$} \\
\hline Upstream-downstream length of elements & $\mathrm{B}$ & 13 \\
Upstream overhang crest length & $\mathrm{B}_{\mathrm{o}}$ & 4 \\
Downstream overhang crest length & $\mathrm{B}_{\mathrm{i}}$ & 3 \\
Base length & $\mathrm{B}_{\mathrm{b}}$ & 6 \\
Wall height & $\mathrm{P}$ & 6 \\
Width of a unit & $\mathrm{W}_{\mathrm{u}}$ & 3.7 \\
Inlet key width & $\mathrm{W}_{\mathrm{i}}$ & 1.6 \\
Outlet key width & $\mathrm{W}_{\mathrm{o}}$ & 1.3 \\
Crests \& wall thickness & $\mathrm{T}_{\mathrm{s}}=\mathrm{T}_{\mathrm{i}}=\mathrm{T}_{\mathrm{o}}$ & 0.4 \\
Total developed length of a unit & $\mathrm{L}_{\mathrm{u}}$ & 28.9 \\
Developed length ratio of a unit & $\mathrm{n}_{\mathrm{u}}$ & 7.8 \\
Aspect ratio & $2 \mathrm{~W}_{\mathrm{u}} / \mathrm{P}$ & 1.23 \\
Parapet walls height & $\mathrm{P}_{\mathrm{pi}, \mathrm{o}, \mathrm{s}}$ & 0.8 \\
Parapet walls crest thickness & $\mathrm{T}_{\mathrm{px}}$ & 0.2 \\
Nose length (triangular profile) & $\mathrm{B}_{\mathrm{n}}$ & 2 \\
\hline
\end{tabular}

$(*)$ See Pralong et al. 2011 


\section{PHYSICAL MODELLING}

\subsection{Description of the physical scaled model}

An experimental set-up of the new additional spillway of Gage II dam, has been constructed at the Laboratory of Hydraulic Constructions (LCH) of the Ecole Polytechnique Fédérale de Lausanne (EPFL) using a geometrical scale factor of 1:40. The model was operated respecting the Froude similarity that preserves the ratio of inertial to gravitational forces in the model like in prototype. It covers an area of $160 \times 160 \mathrm{~m}^{2}$ of the reservoir including the bank topography where the new spillway is located.

The flap gate, the designed PKWeir and the restitution side channel have been constructed with grey PVC material. The topography of the reservoir was reproduced by a series of PVC vertical profiles filled with sand and covered by a thin layer of cement. Figure 5a presents the new spillway set-up with a movable flap gate that can have two different positions corresponding to the hot and cold seasons. Figure $5 \mathrm{~b}$ shows the models of the spillway and part of the water reservoir after their assembly.
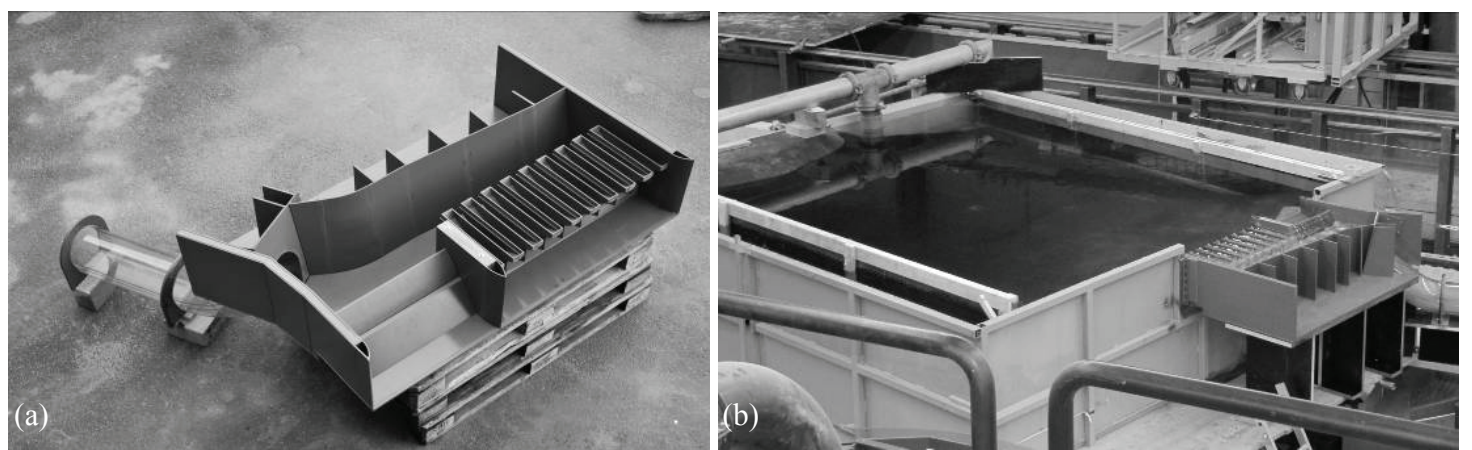

Figure 5. Physical scaled model: a) New spillway (PKWeir, flap gate, and side channel); b) The model with the reservoir topography and the water supply system.

The tailrace tunnel has been modeled using transparent PVC material rolled around a special mould to produce the horse shoe cross-section of the tunnel. A limited part of the topographic area of the valley downstream from the dam has been also reproduced to examine the jet trajectory issued from the deflector of the tunnel.

The model is supplied by a variable speed pump and the input water discharge is measured by an electromagnetic flowmeter, with $1 \%$ accuracy. The water level in the tank was measured by two ultrasonic sensors with $\pm 1 \mathrm{~mm}$ accuracy while the water depth in the restitution channel was estimated using two limnimeters fixed against the side walls of the channel near the PKWeir and the flap gate weir.

\subsection{PKWeir capacity}

The spillway capacity has been evaluated based on the physical measurements performed for three different geometries. The number of units $\mathrm{N}_{\mathrm{u}}$ and the total width $\mathrm{W}$ of the PKWeir are listed in Table 3 for the three tested configurations. The developed length, L, of the PKWeir along its overflowing crest axis is also shown in Table 3. The difference between Geometries 1 and 2 lies only in the number of units of the PKWeir. The spillway in Geometries 2 and 3 has the same PKWeir configuration but with different flap gate width. For each Geometry, different flood scenarios during hot and cold periods have been tested.

Table 3. Global geometric parameters of the tested geometries of the new spillway.

\begin{tabular}{ccccc}
\hline Geometry & $\begin{array}{c}\mathrm{N}_{\mathrm{u}} \\
{[\text { unit] }}\end{array}$ & $\begin{array}{c}\mathrm{W} \\
{[\mathrm{m}]}\end{array}$ & $\begin{array}{c}\mathrm{L} \\
{[\mathrm{m}]}\end{array}$ & $\begin{array}{c}\text { Flap gate width } \\
{[\mathrm{m}]}\end{array}$ \\
\hline 1 & 9 & 34.0 & 264 & 20.0 \\
2 & 7 & 26.6 & 201 & 20.0 \\
3 & 7 & 26.6 & 201 & 27.4 \\
\hline
\end{tabular}


The experimental results regarding the output discharge of the spillway and the water level in the reservoir are presented in Figure 6 for both hot and cold periods. During the hot period (Fig. 6, left), the main discharge is evacuated by the PKWeir. As expected, the spillway capacity is greater for Geometry 1 than for the two others (26\% more than Geometry 2 and $19 \%$ more than Geometry 3), as the total discharge is proportional to the number of PKWeir units. The comparison of Geometries 2 and 3 shows that the width of the flap gate has a small impact on the capacity. However, the discharge capacity is $6 \%$ higher in Geometry 3.
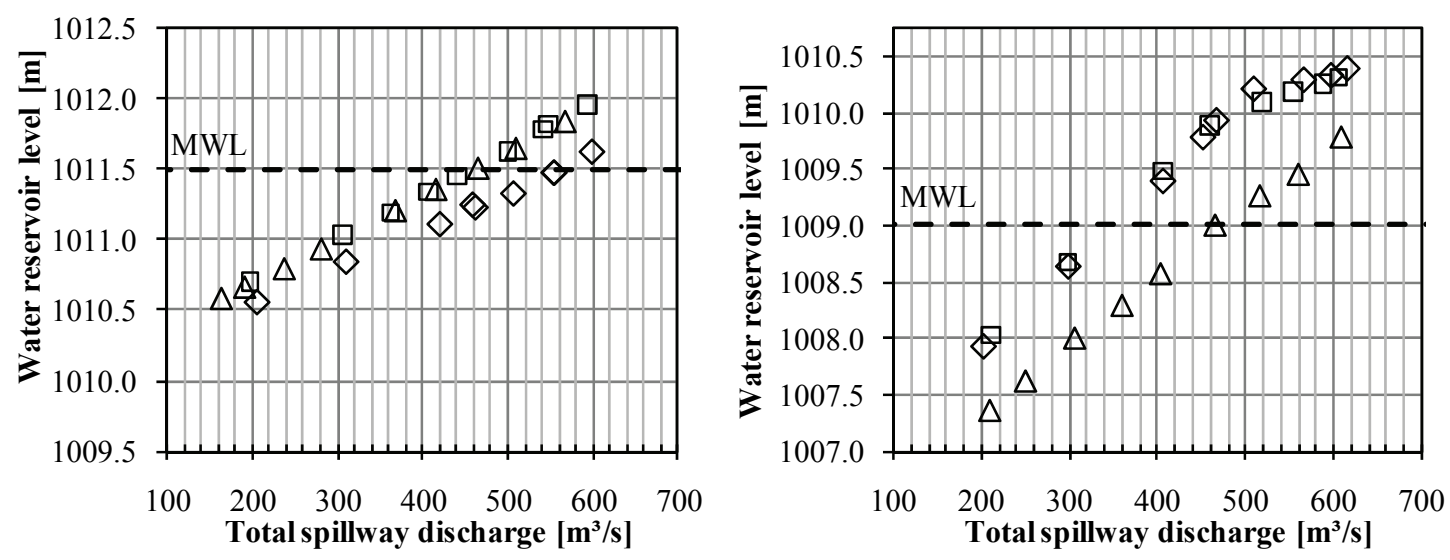

$$
\diamond \text { Geometry } 1 \quad \square \text { Geometry } 2 \quad \Delta \text { Geometry } 3
$$

Figure 6. Spillway capacity for the three different geometries during hot (left) and cold periods (right).

The spillway capacity relative to the cold period scenario is shown in Figure 6 (right). During this period of the year, the floods are evacuated only through the flap gate weir. During the tests, the maximum operation level has been modified by EDF from el. 1010 to $1009 \mathrm{~m}$. The two Geometries 1 and 2 had already been tested for the maximum operation level $1010 \mathrm{~m}$. The tests done with Geometry 3 have been adapted to the new maximum operation level. This explains why the discharge points are shifted down for this latter spillway configuration.

The results show that Geometry 3 with a PKWeir of 7 units and a flap gate width of $27.4 \mathrm{~m}$ satisfies the flood evacuation capacity and the reservoir level constraints for 1000 years return period floods, during hot and cold periods. This geometry, called Optimized Preliminary Configuration (OPC), was adopted as start configuration for the following physical tests dedicated to the flow interaction inside the channel.

Figure 7 shows an interesting comparison of the PKWeir capacity versus water head for different projects that have been designed or built in France (Leite et al. 2007, Bieri et al. 2010). It shows that the capacity of Gage II PKWeir spillway is significantly improved. This is mainly due to the additional experience gained by designers in the geometrical optimization of PKWeirs (Vermeulen et al. 2011).
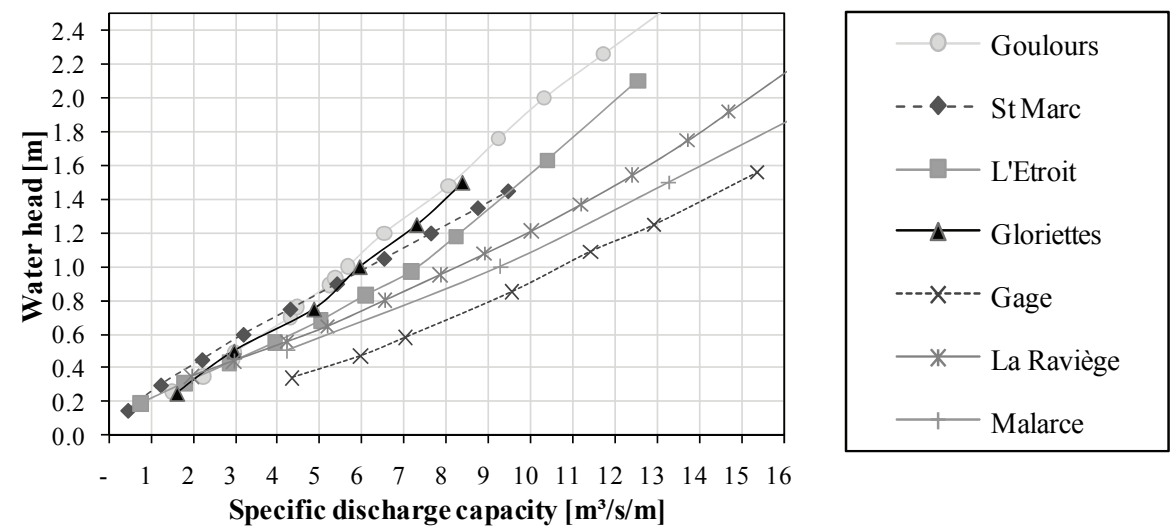

Figure 7. PKWeir unit discharge capacity versus water head for different projects including the Gage II spillway. 


\subsection{Flow Interaction between the flap gate and the PKWeir}

By spilling into the same side channel, the flap gate and the PKWeir overtopping jets interact together and with the flow inside the channel.

In the preliminary design, the PKWeir was placed in the upstream part of the side channel and the flap gate in its downstream part in front of the entrance of the tailrace tunnel (Figure $5 \mathrm{a})$. The width of the side channel is variable and grows from $7.6 \mathrm{~m}$ in the upstream side to around $13.5 \mathrm{~m}$ in the downstream side near the tunnel entrance. The interaction of both the PKWeir and the flap gate weir has been studied for two different configurations: (i) the Optimized Preliminary Configuration (OPC), and (ii) the (SOPC) configuration obtained from the OPC by switching the relative positions of the PKWeir and the flap gate weir.

Figure 8 (left) shows the experimental results for these two configurations, during hot period. The new spillway conserves its capacity for both configurations. The PKWeir, placed in front of the tunnel entrance, creates less turbulent flow in the side channel compared to the original design (Figs. 9a, 9b).
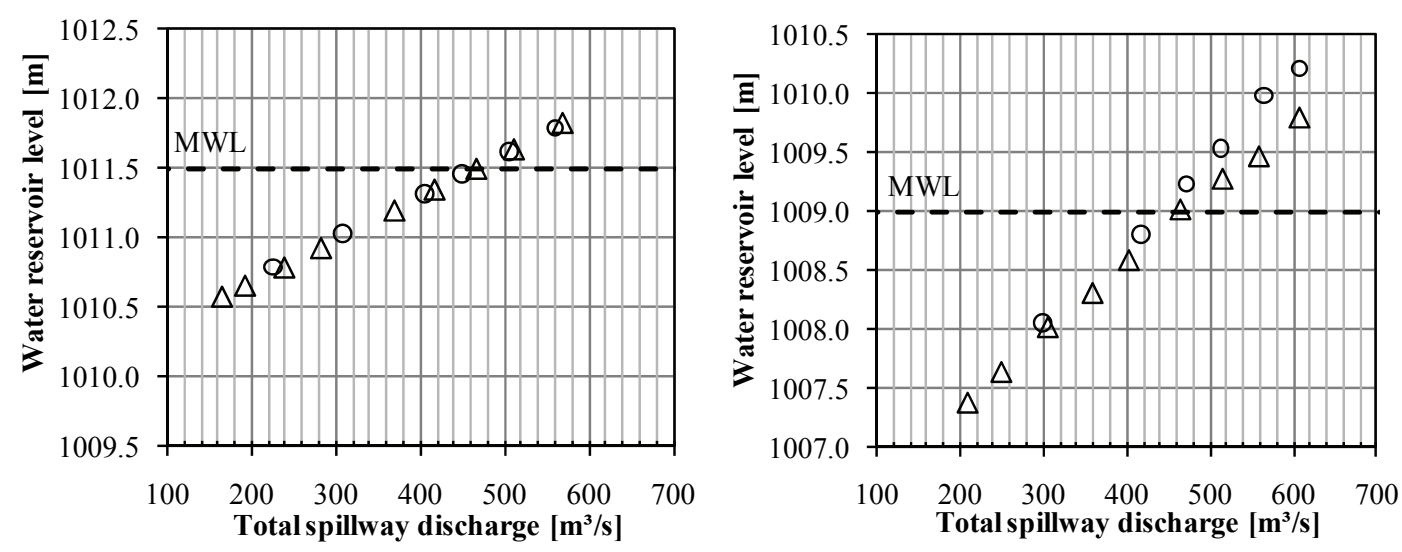

$$
\triangle \mathrm{OPC}
$$

O SOPC

Figure 8. Spillway capacity for the two configurations OPC and SOPC during hot (left) and cold (right) periods.

During cold period, the water flow evacuated by the opened flap gate is strongly decelerated by the turbulent flow generated in the side channel before entering the tunnel. Therefore, the water level rises in the upstream side of the channel, approaching the crest level of the flap gate. This induces a significant drop of the spillway capacity especially near and above the maximum reservoir level (Figs. 8 (right), 9c and 9d).

The first conclusion coming out from the above observations penalizes the SOPC configuration. In spite of the presence of relatively high turbulences in the channel flow of the OPC configuration, this latter has been retained for the following test series.
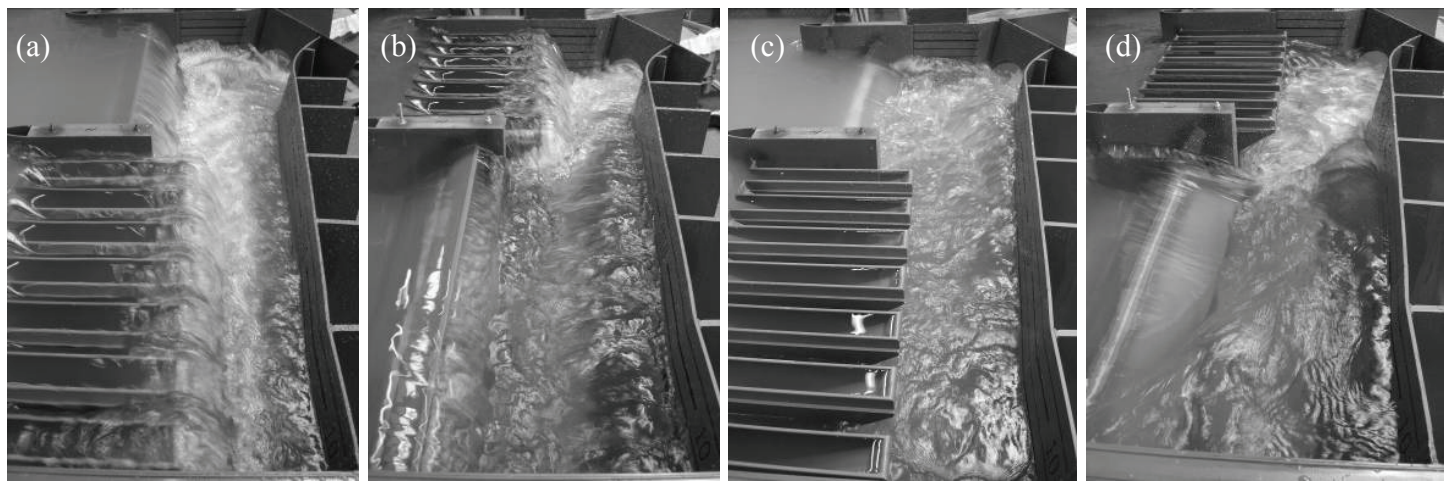

Figure 9. Flow in the side channel for the 5000 years return period flood: a) and b) during hot period; c) and d) during cold period; a) and c) for the Optimized Preliminary Configuration (OPC); b) and d) for the Switch Optimized Preliminary Configuration (SOPC). 
Another interaction phenomenon has been observed between the PKWeir output flow near the flap gate and the jet of the latter. As shown in Figure 10 (left), the flap gate jet does not adhere to the central spillway pier. The flow evacuated by the near PKWeir unit infiltrates under the flap gate jet and creates instable flow oscillations. In order to protect the output flap gate jet from this underneath flow, it was decided to move the longitudinal axis of the flap gate 3 meters towards the reservoir. The flap gate jet will be then protected by the central spillway pier (Fig. 10 right).

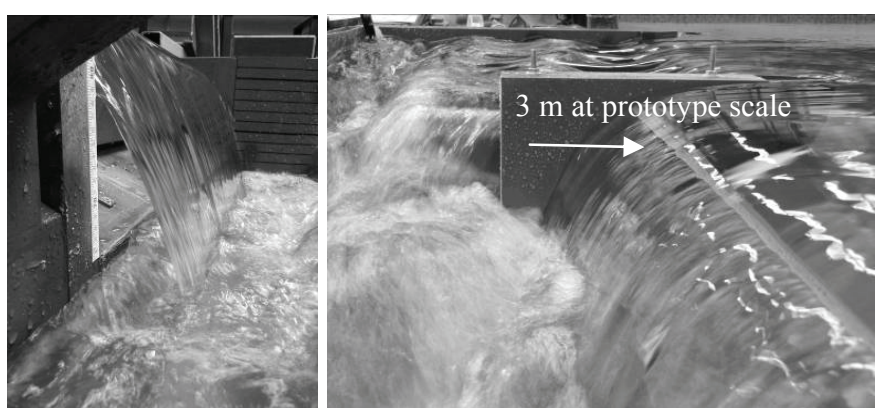

Figure 10. Downstream view of the flap gate jet in the original axial position (left) and in the adapted axial configuration (right).

\subsection{Influence of the water level in the side channel on the PKWeir capacity}

The final optimization step concerns the side channel dimensions and slope. Different geometries have been tested and compared relative to their flow capacity and general behavior (Fig. 11). The modifications of the side channel geometry have been done by changing its width, height and the slope of its bottom.

A first series of tests has been carried out using two different channel depths. The so-called "Original design" (Od) has a horizontal bottom level at el. $998 \mathrm{~m}$. This channel depth was used in all the previous tests discussed above. The configuration called "Od $+2 \mathrm{~m}$ ", which corresponds to the preliminary design, has the horizontal bottom level at el. $1000 \mathrm{~m}$. To accelerate the flow, two longitudinal channel bottom slopes of 1 and 5\% have been simultaneously tested. This defines two new configurations called "Od + longitudinal slope 1\%" and "Od + longitudinal slope 5\%", respectively. Another configuration for the channel bottom with a longitudinal slope of $10 \%$ applied on the first $15 \mathrm{~m}$ upstream has been also tested ("Od + upstream slope $10 \%$ ). Finally, the width of the channel has been reduced by $1 \mathrm{~m}$ for the "Od" and "Od $+2 \mathrm{~m}$ " configurations.
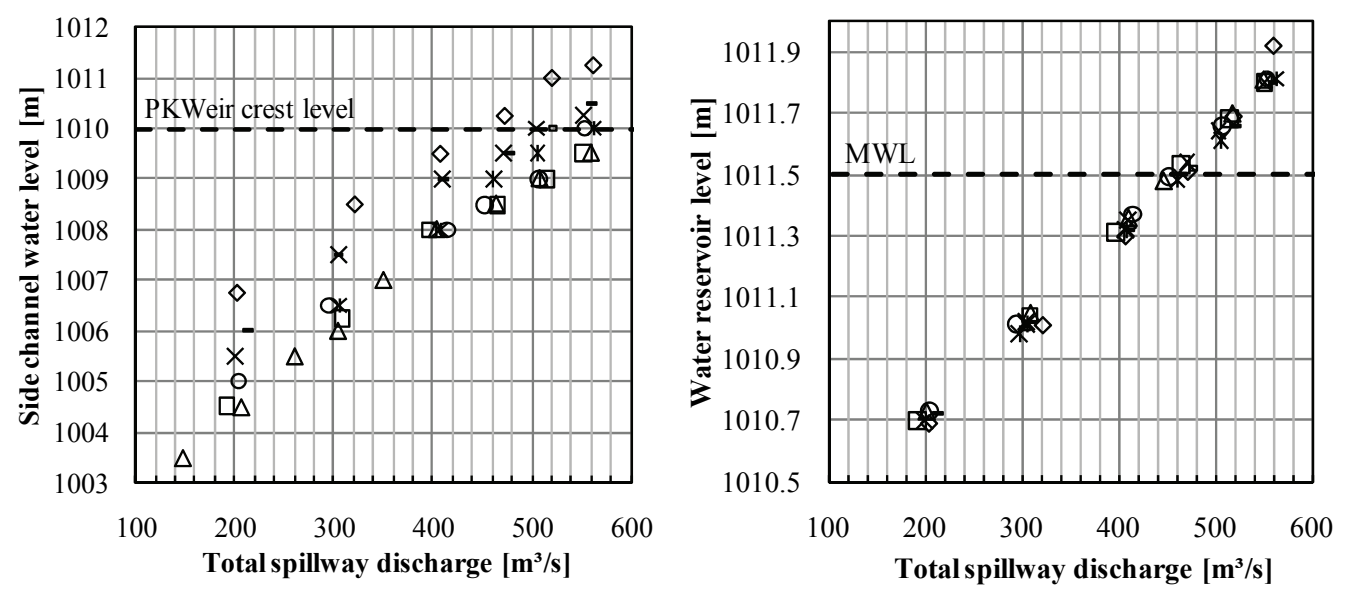

\begin{tabular}{|lll|}
\hline Original design & $-\mathrm{Od}+2 \mathrm{~m}$ & O Od + Long. slope $1 \%$ \\
$\times$ Od + long. slope 5\% & $\square$ Od + upstream slope $10 \%$ & * Od + channel width $-1 \mathrm{~m}$ \\
$\diamond \mathrm{Od}+2 \mathrm{~m}+$ channel width $-1 \mathrm{~m}$ & \\
\hline
\end{tabular}

Figure 11. Water level at the upstream end of the side channel (left) and spillway capacity (right) for the different tested channel geometries. 
For all the tests carried out on each of the defined configurations, the capacity of the spillway and the water level at the upstream end of the side channel have been measured, in order to evaluate the downstream water level effect on the PKWeir output capacity (Fig.11).

The obtained results show that the different tested configurations of the side channel have a very low impact on the discharge capacity of the new spillway, even so the PKWeir crest lies below the channel water level. Therefore, the only criteria to be considered for the choice of the optimal channel configuration were the flow capacity of the entrance of the tailrace tunnel and the rock excavation volume. The side channel configuration "Od $+2 \mathrm{~m}$ " revealed to be the best one. It offers also a sufficient capacity for the 5000 years return period floods.

\section{CONCLUSIONS}

The experimental study presented in this paper has been a powerful support for designers to optimize the new spillway structure of the Gage II dam. Such complicated spillway, composed of a PKWeir, a flap gate weir and a side evacuation channel, is the master piece for reducing the water pressure loads on the arch dam during the cold season and for evacuating the new estimated flood events that almost triples the old flow peak used for the original design.

The preliminary spillway configuration that has been designed by the EDF Engineers could be optimized through a series of physical tests carried out in the Laboratory of Hydraulic Constructions (LCH-EPFL) in Lausanne. The optimized configuration is the combination of a 7 units PKWeir and a $27.4 \mathrm{~m}$ wide flap gate weir whose longitudinal axis was shifted upstream by $3 \mathrm{~m}$ relative to the PKWeir axis. The flap gate weir reveals to be more efficient when it is located in front of the entrance of the tailrace tunnel. The side channel depth and width were maintained as in the preliminary design.

In this ongoing project, additional laboratory tests will be carried out to study the flow in the tailrace tunnel and the behavior of the jet issued from a flip bucket. These tests are focused on the optimization of the geometry of the flip bucket with the aim to mitigate the jet impact on the river bed downstream.

\section{REFERENCES}

Bieri, M., Federspiel, M., Boillat J-L., Houdant B. and Delorme, F. 2010. Spillway discharge capacity at Gloriettes dam. Hydropower and Dams. Issue Five, 88-93.

Falvey, T. H. 2003. Hydraulic design of labyrinth weirs. ASCE Press.

Flow-3D 2010, Computational fluid dynamics software. Flow science Inc (www.flow3d.com)

Hager, W. H. \& Schleiss, A.J. 2009. Traité de Génie Civil Volume 15 - Constructions Hydrauliques, Ecoulements stationnaires. Switzerland : PPUR - Presses Polytechniques Romandes.

Leite Ribeiro, M., Boillat, J-L., Schleiss, A., Laugier, F. and Albalat, C. 2007. Rehabilitation of St-Marc dam - Experimental optimization of a Piano Key Weir. 32nd Congress of IAHR, The International Association of Hydraulic Engineering and Research. Venice, Italy.

Leite Ribeiro, M., Bieri, M., Boillat, J-L., Schleiss, A., Delorme, F. and Laugier, F. 2009. Hydraulic capacity improvement of existing spillways - Design of piano key weirs. 23rd Congress of Large Dams. Question 90, Response 43. 25-29 May 2009. Brasilia, Brazil.

Pralong, J., Blancher, B., Laugier, F., Machiels, O., Erpicum, S., Pirotton, M., Leite Ribeiro, M., Boillat. J-L., and Schleiss, A.J. 2011. Proposal of a naming convention for the Piano Key Weir geometrical parameters. International Workshop on Labyrinth and Piano Key weirs, Liège, Belgium.

United States Department of the Interior 1987. Design of Small Dams. A water resources technical publication, Third edition.

Vermeulen, J. \& Faramond, L. \& Gille, C. 2011. Lessons learnt from design and construction of EDF first Piano Key Weirs. Workshop on Labyrinth and Piano Key Weir, Liège. Belgium 